Research Article

\title{
Pattern of adverse drug reactions in new smear positive patients of pulmonary tuberculosis treated under directly observed treatment short course
}

\author{
Aradhna Sharma ${ }^{1}$, Dinesh Kansal ${ }^{1}$, Kiran Katoch ${ }^{2}$, Parveen Kumar Sharma ${ }^{1}$, \\ Rekha Bansal ${ }^{3}$, Tarun Sharma ${ }^{4}$
}

${ }^{1}$ Department of Pharmacology, Dr. RPGMC Kangra at Tanda, Himachal Pradesh, India,

${ }^{2}$ National JALMA Institute of Leprosy and Other

Mycobacterial Diseases, Agra,

Uttar Pradesh, India,

${ }^{3}$ Department of Pulmonary

Medicine, ${ }^{4}$ Department of

Medicine, Dr. RPGMC Kangra,

Tanda, Himachal Pradesh, India

Received: 25 April 2016

Accepted: 03 June 2016

\section{*Correspondence to:}

Dr. Aradhna Sharma,

Email: draradhnasharma@ gmail.com

Copyright: (C) the author(s), publisher and licensee Medip Academy. This is an openaccess article distributed under the terms of the Creative Commons Attribution NonCommercial License, which permits unrestricted noncommercial use, distribution, and reproduction in any medium, provided the original work is properly cited.

\section{ABSTRACT}

Background: Directly observed treatment short course (DOTS), a combination therapy, drugs are administered for six to eight months in patients diagnosed with tuberculosis, increases the risk of adverse drug reactions. The objective of this study was to study the adverse drug reaction profile of new sputum smear positive (NSP) patients of pulmonary tuberculosis (PTB) treated under DOTS. A prospective observational study was carried out in Dr. RPGMC Kangra at Tanda, Himachal Pradesh, India over a period of six months.

Methods: The study included 130 newly diagnosed TB patients on anti-TB treatment under DOTS. A symptom based approach was followed for monitoring ADRs. The severity was assessed by Modified Hartwig scale and causality by WHO-UMC probability scale. Data was expressed as percentages for discrete variables using Microsoft excel.

Results: Out of the total 130, 84 patients experienced ADRs with an overall incidence of $64.6 \% .45(34.6 \%)$ patients showed single ADR whereas $39(30 \%)$ patients had two or more ADRs. Gastritis alone was present in $36(27.8 \%)$ patients followed by itching $2(1.5 \%)$, hypersensitivity $2(1.5 \%)$, arthralgia 2 (1.5\%), generalized weakness $2(1.5 \%)$ and jaundice in $1(0.8 \%)$ patients. Vomiting was present in $29(22.2 \%)$ patients, neuropathy in $4(3.1 \%)$ patients, arthralgia in $2(1.5 \%)$ patients, hypersensitivity, jaundice, itching and generalized weakness in $1(0.8 \%)$ patient each. $21(16.2 \%)$ patients experienced mild , $56(43.1 \%)$ had moderate and only $7(5.4 \%)$ had severe ADRs. All the ADRs were possible in nature.

Conclusions: The incidence of ADRs was $64.6 \%$ and GI irritation was found to be most common ADR reported by $57.6 \%$ patients.

Keywords: Tuberculosis, DOTS, ADRs

\section{INTRODUCTION}

Tuberculosis is one of the major health problems, with India being the highest TB burden country. Directly observed treatment short course (DOTS) was introduced in India in 1993 as part of revised national tuberculosis control programme (RNTCP). ${ }^{1}$ Combinations of isoniazid
(INH), rifampicin (RFP), pyrazinamide (PZA), ethambutol (EMB), are administered every other day for 6 months. ${ }^{2}$ The therapeutic efficiency of DOTS, combination therapy is well defined but certain studies suggest that more than $5 \%$ of the patients on anti-tubercular drugs develop ADRs., 
As the combinations of drugs are used for prolonged periods of time, it is likely that the ADRs of one drug are potentiated by the companion drugs used. All anti tubercular drugs can produce ADRs and involves almost all systems in the body such as gastrointestinal tract, liver, skin, nervous system, otto-vestibular apparatus and eyes. 5 The nature of ADRs also changes due to population variations with respect of genetic, environmental and dietary factors. ${ }^{6}$ The Adverse Drug Reactions (ADRs) to the drugs is one of the major reasons for the patients default from the treatment. ${ }^{6}$

ADRs not only contribute to the noncompliance to the therapy but because of their severity also lead to stoppage of treatment occasionally which may further lead to development of drug resistance strains. These resistant strains require second line drugs for treatment which have higher cost and more serious adverse drug reactions.? ADRs mostly tend to occur in the first three months of treatment. ${ }^{8}$ As to the profile of adverse drug reactions (ADRs) due to DOTS, there is no report available in patients receiving anti-tuberculosis chemotherapy in Himachal, India.

The primary objective was to study the adverse drug reaction profile of new sputum smear positive (NSP) patients of pulmonary tuberculosis (PTB) treated under DOTS in Dr. RPGMC, Kangra at Tanda, Himachal Pradesh, India.

\section{METHODS}

\section{Study design and sample selection}

This observational prospective study was carried out in the Department of Pulmonary Medicine, Dr. Rajendra Prasad Government Medical College and Hospital Kangra at Tanda, Himachal Pradesh, India from $1^{\text {st }}$ April, 2012 to $31^{\text {st }}$ October, 2012. The study was done after obtaining the approval from institutional ethics committee (No. HFW-DRPGMC/Ethics/2012/11-12). The study included 130 consecutively diagnosed TB patients attending OPD of department of pulmonary medicine.

\section{Inclusion and exclusion criteria}

All the new smear positive patients of age $>12$ years of either sex and willing to participate were included in the study. Patients with HIV positive serology and with renal and liver disease were excluded.

\section{Investigation and follow up}

After obtaining the written informed consent from the patients, complete present and past history of the patient about the signs and symptoms as well as treatment history was taken in detail. Various laboratory investigations like complete hemogram, complete urine examination, LFTs, RFTs, visual acuity, and fundus examination were done. All the patients received category 1 DOTS as per RNTCP guidelines. In the initial Intensive Phase (IP) DOTS was administered [H (600 $\mathrm{mg}$ ), R (450 mg) (Pts who weighed $60 \mathrm{~kg}$ or more at the start of treatment received an extra $150 \mathrm{mg}), \mathrm{E}(1200 \mathrm{mg})$ and $\mathrm{Z}(1500 \mathrm{mg})]$, and was given under direct observation thrice a week on alternate days for 2 months (24 doses). On obtaining sputum smear negativity, then in continuation phase $(\mathrm{CP})$, patients received $\mathrm{H}(600 \mathrm{mg})$ and R (450 mg) thrice a week for 4 months (54 doses). Patients were followed up by the investigator till the completion of DOTS.

\section{Reporting of adverse drug reaction}

The symptom based approach for monitoring of adverse drug events was followed. Patients who reported any adverse drug event or any symptom were called and managed either on OPD basis or were admitted and managed with appropriate investigations and treatment.

\section{Assessment of adverse drug reactions}

Adverse drug reactions were assessed by timing, pattern and back ground frequency.

Severity of the ADRs were classified according to Hartwig et al as

- Mild reactions which were self-limiting and able to resolve over time without treatment and did not contribute to prolongation of length of stay

- Moderate ADRs were defined as those that required therapeutic intervention and hospitalization prolonged by 1 day but resolved in $<24$ hours or change in drug therapy or specific treatment to prevent a further outcome, and

- Severe ADRs were those that were life-threatening, producing disability and those that. ${ }^{9}$

Prolonged hospital stay or led to hospitalization, required intensive medical care, or led to the death of the patient.

Causality assessment of suspected adverse drug reaction as per WHO-UMC causality assessment scale which quantifies the temporal association as certain, probable, possible, unlikely, conditional/unclassified, unassessable/unclassifiable. ${ }^{10}$

\section{Data and statistical analysis}

Data was expressed as percentages for discrete variables and the analysis was made using Microsoft excel.

\section{RESULTS}

Out of the total 130 patients, 84 patients experienced ADRs with an overall rate of $64.6 \% .45(34.6 \%)$ patients showed single ADR whereas $39(30 \%)$ patients had two or more ADRs (Table 1 and Figure 1). 
Table 1: Adverse drug reactions (ADRs) in patients.

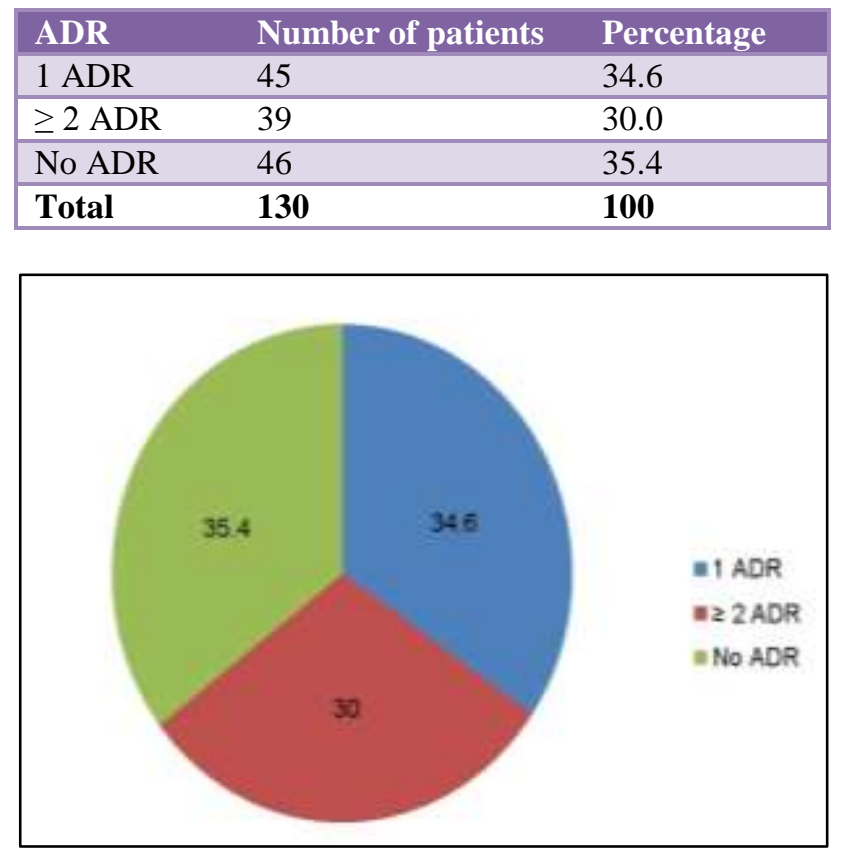

Figure 1: Adverse drug reactions in patients $(\mathrm{N}=130)$.

Gastritis alone was present in 36 (27.8\%) patients followed by itching $2(1.5 \%)$, hypersensitivity $2(1.5 \%)$, arthralgia $2(1.5 \%)$, generalized weakness $2(1.5 \%)$ and jaundice in $1(0.8 \%)$ patients. Two or more ADRs were present in 39 (30\%) patients. Gastritis was common in all the patients. Out of these vomiting was present in 29 $(22.2 \%)$ patients, neuropathy in $4(3.1 \%)$ patients, arthralgia in $2(1.5 \%)$ patients, hypersensitivity, jaundice, itching and generalized weakness in $1(0.8 \%)$ patient each (Table 2).

Table 2: ADRs Profile of patients.

\begin{tabular}{|c|c|c|}
\hline Adverse drug event $\mathbf{N}$ & Number of patients & Percentage \\
\hline \multicolumn{3}{|c|}{ Single adverse drug reaction } \\
\hline Gastritis & 36 & 27.8 \\
\hline Itching & 2 & 1.5 \\
\hline Hypersensitivity & 2 & 1.5 \\
\hline Arthralgia & 2 & 1.5 \\
\hline Jaundice & 1 & 0.8 \\
\hline Generalised weakness & 2 & 1.5 \\
\hline Total & 45 & 34.6 \\
\hline \multicolumn{3}{|l|}{ Two or moreADRs } \\
\hline Gastritis+vomiting & 29 & 22.2 \\
\hline Gastritis+hypersensitivity & 1 & 0.8 \\
\hline Gastritis+neuropathy & 4 & 3.1 \\
\hline Gastritis+arthralgia & 2 & 1.5 \\
\hline $\begin{array}{l}\text { Gastritis+generalized } \\
\text { weakness }\end{array}$ & 1 & 0.8 \\
\hline Gastritis +jaundice & 1 & 0.8 \\
\hline Gastritis +itching & 1 & 0.8 \\
\hline Total & 39 & 30.0 \\
\hline
\end{tabular}

The overall incidence of GI symptoms was $57.6 \%$ and females were more prone to GI symptoms.

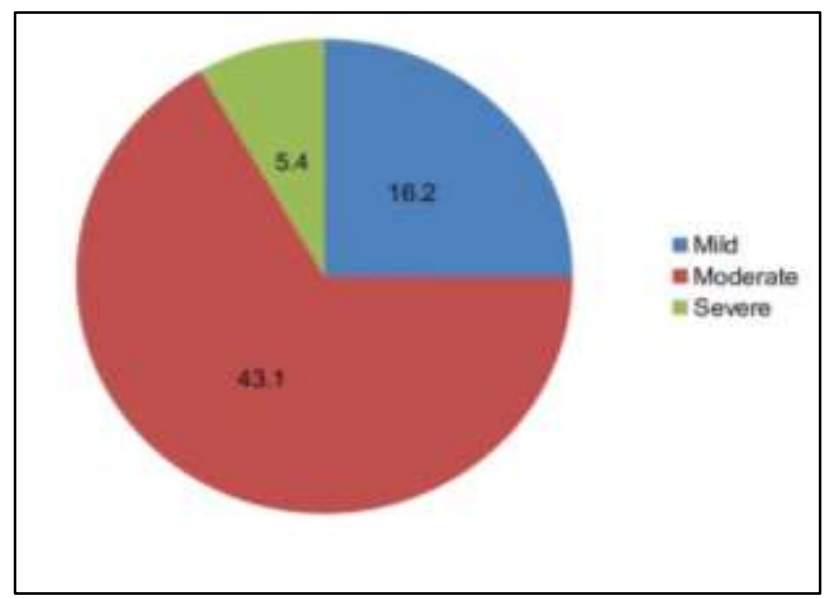

Figure 2: Severity assessment of ADRs.

Out of the total 130 patients, $21(16.2 \%)$ patients experienced mild ADRs, $56(43.1 \%)$ patients had moderate and only $7(5.4 \%)$ patients had severe ADRs. (Table 3 and Figure 2) On causality assessment using WHO causality assessment scale all the ADRs were possible in nature.

Table 3: Severity assessment of ADRs (N=130).

\begin{tabular}{|lll|}
\hline Nature & Number of patients & Percentage \\
\hline Mild & 21 & 16.2 \\
\hline Moderate & 56 & 43.1 \\
\hline Severe & 7 & 5.4 \\
\hline Total & $\mathbf{8 4}$ & $\mathbf{6 4 . 7}$ \\
\hline
\end{tabular}

\section{DISCUSSION}

The incidence of adverse drug reactions in our study was $64.6 \%$ and GI irritation (gastritis+vomiting) was found to be the most common ADR reported by $57.6 \%$ patients. Patients with mild ADR did not require any treatment. Symptoms of gastritis started within a week of the start of treatment. In almost all the patients with gastritis and vomiting, change in dietary habits was recommended. Additional Proton pump inhibitor or histamine antagonist was prescribed in those in which alone dietary advice could not bring relief. None of these patients were dechallenged. Since gastritis is the most common reported ADE, change in dietary habits like low fat diet, bland diet and consumption of cold milk should be recommended in these patients.

Peripheral neuropathy was present in 4 patients. All the patients presented after one month of start of treatment. It was mild to moderate in nature. All the patients were given additional pyridoxine $100 \mathrm{mg}$ daily. None of the ATT was stopped and patients improved without any other intervention. 
Hypersensitivity reaction to ATT was present in 3 patients. One patient had severe hypersensitivity reaction immediately after the first dose of treatment; the treatment regime was changed from HRZE to HES. The reaction subsided immediately after stopping the $\mathrm{R}$ and $\mathrm{Z}$ (dechallenge). Re-challenge was not done in this patient due to ethical reasons. All the four first line drugs can cause hypersensitivity reactions but it is found to be most common with $\mathrm{R}$ and $\mathrm{Z} .{ }^{11}$ Another patient had vasculitis after 1 week of the start of treatment. The patient was admitted and the reaction subsided within a day on its own. The causal association of ATT drugs was not ascertained in this case.

Out of total 84 patients, single ADR was experienced by $45(34.6 \%)$ patients and more than one ADR were experienced by $39(30.0 \%)$ patients.

In the study conducted by Acharaya et al in Karnataka, the incidence of ADRs was $17.02 \%$, with more preponderance in males and gastritis was the commonest complaint. $^{12}$ In another study conducted by Dhingraet al in New Delhi, GI symptoms were most common symptoms and were present in $53 \%$ of patients. ${ }^{13}$ In the study from Nepal by Khetri et al, the incidence of ADR was $54.74 \%$ with equal prevalence in males and females. ${ }^{14}$ Commonest ADR was central nervous system. Two studies from Russia by Chukanov and Tashpulatova reported an incidence of $72.8 \%$ and $60.2 \%$ respectively. ${ }^{15,16}$ The incidence of ADRs may vary from population to population in different regions to a great extent.

Onset of the ADRs is an important factor as some of them appeared very early and others delayed. In our study about $80 \%$ of the ADRs occurred within the first week of therapy. In the study by Dhingra, $67 \%$ of the ADRs occurred in the first four weeks. The average lag in start of treatment and appearance of adverse drug reaction was immediate reaction to 120 days. As some of the ADRs would appear early and would gradually increase while others present only in the initial period and gradually subside with passage of time.

Since DOTS is a combination therapy, it is very difficult to find a causal relationship between individual drug and ADE without de-challenging it which was done only in one patient. Even in that case two medications were stopped and risk of re-challenge was not found feasible.

\section{CONCLUSION}

Identification of adverse drug reaction profile of drugs is not only useful in prevention, early detection and management of ADRs but also helps in drawing long term strategies of treatment with appropriate schedules.

\section{ACKNOWLEDGEMENTS}

We would like to acknowledge all the patients included in the study.

\section{Funding: No funding sources}

Conflict of interest: None declared

Ethical approval: The study was approved by the Institutional Ethics Committee

\section{REFERENCES}

1. Balasubramanian VN, Oommen K, Samuel R. DOT or not? Direct observation of anti-tuberculosis treatment and patient outcomes, Kerala State, India. Int J Tuberc Lung Dis. 2000;4:409-13.

2. World Health Organization. An expanded DOTS framework for effective tuberculosis control. Stop TB Communicable Diseases. Geneva: WHO Press; 2002:1-20.

3. Dhingra VK, Rajpal S, Aggarwal N, Aggarwal JK, Shadab K, Jain SK. Adverse drug reactions observed during DOTS. J Commun Dis. 2004;36:251-9.

4. Chukanov VI, Kaminskaia GO, Livchane E. Frequency and pattern of adverse reactions due to treatment of patients with pulmonary tuberculosis with antitubercular reserve drugs. Probl Tuberk Bolezn Legk. 2004;10:6-10.

5. Govt. of India. DOTS Guidelines. Central TB Division, Directorate General of Health Services, Ministry of Health and Family Welfare, New Delhi. 2005.

6. Devi S, Ramchandran R, Santha S. Adverse reaction to anti-tuberculosis drugs and their management. Bulletin. 1997;4(3):54-5.

7. Stork CM, Hoffman RS. Toxicology of antituberculosis drugs. In: Rom. W. Gary S, Tuberculosis. Newyork: Little, Brown and company; 1996:829-37.

8. Bhargav A, Jain Y. The revised national tuberculosis program in India: Time for revision of treatment regimens and rapid up scaling of DOTS-plus initiative. National Medical Journal of India. 2008;21(4):187-91.

9. Hartwig SC, Siegel J, Schneider PJ. Preventability and severity assessment in reporting adverse drug reactions. Am J Hosp Pharm. 1992;49:2229-32.

10. The use of the WHO-UMC system for standardized case causality assessment. Available at http://www.WHO-UMC.org/graphics /4409.pdf.

11. Girling DJ. Adverse drug effects of anti-tuberculosis drugs. Drugs. 1982;23:56.

12. Tak DK, Acharya ID, Gowrinath K, Rao Padma G M, Subish P. Safety evaluation of anti-tubercular therapy under Revised National Tuberculosis Control Program in India. Journal of Clinical and Diagonostic Research. 2009;(3):1395-1401.

13. DhingraVK, Rajpal S, Aggarwal N, AggarwalnJK, Shadab K, Jain SK. Adverse drug reactions observed during DOTS. J Commun Dis. 2004;36(4):251-9. 
14. Chhetri KA, Saha A, Verma SC, Palaian S, Mishra P, Shankar PR. A study of adverse drug reactions caused by first line anti tubercular drugs used in DOTS therapy in Western Nepal, Pokhra. JPMA. 2008;58:531.

15. Chukanov VI, Kaminskaia GO, Livchane E. Frequency and pattern of adverse reactions due to treatment of patients with pulmonary tuberculosis with anti-tubercular drugs. Probl Tuberk Bolezn Legk. 2004;10:6-10.

16. Tashpulatova FK. Prevention of adverse reactions of anti-tuberculousdrugs in pulmonary tuberculosis in patients with different genetic background. Probl Tuberk Bolezn Legk. 2003;6:17-20.

Cite this article as: Sharma A, Kansal D, Katoch K, Sharma PK, Bansal R, Sharma T. Pattern of adverse drug reactions in new smear positive patients of pulmonary tuberculosis treated under directly observed treatment short course. Int J Basic Clin Pharmacol 2016;5:1397-1401. 